\title{
Hydrogen sulfide ameliorates doxorubicin-induced myocardial fibrosis in rats via the PI3K/AKT/mTOR pathway
}

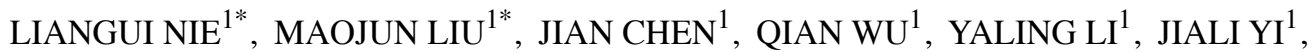 \\ $\mathrm{XIA} \mathrm{ZHENG}^{1}$, JINGJING ZHANG ${ }^{1}, \mathrm{CHUN} \mathrm{CHU}^{2}$ and $\mathrm{JUN} \mathrm{YANG}^{1}$ \\ ${ }^{1}$ Department of Cardiology, The First Affiliated Hospital of University of South China; ${ }^{2}$ Department of Pharmacy, \\ The Second Affiliated Hospital of University of South China, Hengyang, Hunan 421001, P.R. China
}

Received August 3, 2019; Accepted January 8, 2021

DOI: $10.3892 / \mathrm{mmr} .2021 .11938$

\begin{abstract}
The present study aimed to determine the role and regulatory mechanism of hydrogen sulfide $\left(\mathrm{H}_{2} \mathrm{~S}\right)$ in the amelioration of doxorubicin-induced myocardial fibrosis in rats. It is hypothesized that the PI3K/AKT/mTOR signaling pathway is regulated to inhibit endoplasmic reticulum stress (ERS) and autophagy to reduce myocardial fibrosis. A total of 40 adult male Sprague Dawley rats were randomly divided into 4 groups ( $\mathrm{n}=10 /$ group). The 4 groups included the normal control group (control group), model group [doxorubicin (Dox) group], $\mathrm{H}_{2} \mathrm{~S}$ intervention model group $\left(\mathrm{H}_{2} \mathrm{~S}+\right.$ Dox group $)$ and $\mathrm{H}_{2} \mathrm{~S}$ control group $\left(\mathrm{H}_{2} \mathrm{~S}\right.$ group). The model used in the present study was constructed by administering intraperitoneal injections of doxorubicin ( $3.0 \mathrm{mg} / \mathrm{kg}$ every other day; total of 6 injections). In addition, the intervention factor, NaHS and the donor of $\mathrm{H}_{2} \mathrm{~S}$, was also administered by intraperitoneal injection (56 $\mu \mathrm{mol} / \mathrm{kg} /$ day), which lasted a month. Pathological changes in the rats were observed using Masson staining and transmission electron microscopy, while the protein expression levels of MMPs/TIMPs, transforming growth factor- $\beta 1$, cystathionine lyase and PI3K/AKT/mTOR, which are autophagy-related and ERS-related proteins were detected in myocardial tissues using western blot analysis. The gene expression levels of collagen
\end{abstract}

Correspondence to: Professor Jun Yang, Department of Cardiology, The First Affiliated Hospital of University of South China, 69 Chuanshan Road, Hengyang, Hunan 421001, P.R. China

E-mail: yangjunincn@163.com

Dr Chun Chu, Department of Pharmacy, The Second Affiliated Hospital of University of South China, 35 Chuanshan Road, Hengyang, Hunan 421001, P.R. China

E-mail: yjchuchun@163.com

*Contributed equally

Abbreviations: $\mathrm{H}_{2} \mathrm{~S}$, hydrogen sulfide; NaHS, sodium hydrosulfide; MMPs, matrix metalloproteinases; TIMPs, tissue inhibitor of metalloproteinases; BCA, bicinchoninic acid

Key words: hydrogen sulfide, doxorubicin, myocardial fibrosis, $\mathrm{PI} 3 \mathrm{~K} / \mathrm{AKT} / \mathrm{mTOR}$ signaling pathway, endoplasmic reticulum stress, autophagy type I $\alpha-2$ chain and collagen type III $\alpha-1$ chain were detected using reverse transcription-quantitative PCR and the quantification of myocardial $\mathrm{H}_{2} \mathrm{~S}$ content was performed using ELISA. In the Dox group compared with that in the control group, myocardial fibers were significantly disordered, while the protein expression levels of ERS-related and autophagy-related proteins were increased markedly, and the expression levels of PI3K/AKT/mTOR proteins were reduced markedly. The aforementioned changes were markedly reversed following $\mathrm{H}_{2} \mathrm{~S}$ intervention, which indicated that $\mathrm{H}_{2} \mathrm{~S}$ exerts a positive protective effect on doxorubicin-induced myocardial fibrosis. The protective mechanism of $\mathrm{H}_{2} \mathrm{~S}$ intervention in myocardial fibrosis is hypothesized to be associated with the inhibition of overactivation of the ER and that of autophagy via upregulation of the PI3K/AKT/mTOR pathway.

\section{Introduction}

The cardiac toxicity that occurs during long-term use of antitumor drugs has attracted increasing attention, particularly antharcycline antitumor drugs. Doxorubicin (Dox) is a highly potent antharcycline antitumor drug and is an important component of classical chemotherapy regimens for lymphoma, leukemia and a variety of other solid tumors, including breast cancer and osteosarcoma. Despite the antitumor effect of Dox, it has been reported to cause noticeable cardiac toxicity, which imposes severe restrictions on the application of Dox and other antharcycline antitumor drugs in clinical practice, for example, in patients with underlying cardiac diseases. Chronic cardiac toxicity caused by Dox is one of the most important side effects of the drug and manifests in congestive heart failure and/or cardiomyopathy (1-2). Previous studies have reported that the mechanism involved in the occurrence of cardiac toxicity and dilated cardiomyopathy (DCM) induced by Dox is associated with the damage caused by reactive oxygen series, calcium overload, mitochondrial dysfunction, apoptosis and autophagy (3-5). However, this remains unclear. At present, there are a limited number of drugs that can be used for alleviating Dox-induced cardiac toxicity. At present, dexrazoxane is a rare drug that can alleviate myocardial toxicity caused by anthracycline antitumor drugs, however, it displays adverse reactions, including neutropenia, and its underlying mechanism of action is not completely understood (6). The 
development of a safer and more effective drug or method to antagonize the cardiac toxicity resulting from Dox and other antharcycline antitumor drugs poses a significant challenge for modern medicine.

The pathological changes in the heart that are caused by Dox in adult patients are predominantly DCM. Therefore, Dox-induced cardiomyopathy is considered as the primary method to construct animal models of DCM (1). It has been confirmed in rabbit and rat animal models of DCM that Dox causes clinical symptoms, such as cardiac dilatation, arrhythmia, cardiac insufficiency and even heart failure in some cases, which is highly similar to the occurrence and development of DCM in patients (7-8). Myocardial fibrosis plays a crucial role in the occurrence and development of Dox-induced cardiac damage and DCM (9); however, the underlying mechanisms are complex and are not completely understood. Some studies have demonstrated that autophagy, endoplasmic reticulum stress (ERS) and cell apoptosis are potentially involved in the occurrence and development of myocardial fibrosis (10-12). Despite this, the specific regulatory mechanism of Dox-induced myocardial fibrosis remains unclear. Therefore, a further exploration of this mechanism is essential for understanding the pathogenesis of Dox-induced myocardial fibrosis and DCM.

Myocardial fibrosis is frequently caused by increased extracellular matrix (ECM) synthesis and its delayed degradation for various reasons, thus resulting in extensive ECM deposition in myocardial interstitium. The imbalance between MMPs and TIMPs is associated with ECM deposition, as well as the occurrence and development of myocardial fibrosis. TGF- $\beta$ is hypothesized to be involved in the mechanism of occurrence of myocardial fibrosis by regulating cell growth, proliferation and differentiation, activating cardiac fibroblasts and enhancing the expression of MMPs (13-16).

$\mathrm{H}_{2} \mathrm{~S}$, a newly discovered gaseous signal molecule performs a variety of anti-inflammatory, -oxidative and -apoptotic biological functions. Previous studies have reported the anti-myocardial fibrosis effect exerted by $\mathrm{H}_{2} \mathrm{~S}$ in animal models of diabetic cardiomyopathy, uremia cardiomyopathy and numerous other diseases (17-19); however, whether $\mathrm{H}_{2} \mathrm{~S}$ can be effective in improving Dox-induced myocardial fibrosis has yet to be ascertained.

The PI3K/AKT/mTOR pathway is a common cell signaling pathway involved in various pathological and physiological processes in mammals and participates in the regulatory mechanism of the cell cycle and cell fate (20). It is hypothesized that this pathway is activated by ERS and negatively regulates autophagy (21). The activation of PI3K is hypothesized to activate and phosphorylate the downstream kinase, AKT. mTOR, an essential downstream kinase in the PI3K/AKT pathway, is also phosphorylated and activated by PI3K, and is a significant factor in the initialization phase of autophagy, to negatively regulate autophagy. Some studies have demonstrated that anoxia, oxidative stress, excessive activation of ERS and other detrimental factors suppress the activity of PI3K, thus inhibiting the activation of PI3K/AKT/mTOR and inducing cell autophagy. LC3 and Beclin-1 are autophagy markers and are commonly used for the evaluation of the degree of autophagy of cells. LC3 is a mammalian homologue of the yeast autophagy-related gene, Atg8. There are two forms that can be converted to each other, namely LC3II and LC3I, while LC3II is considered as a marker of autophagosome formation (22-24). LC3 has a close relationship with the formation of autophagosome and a positive association with the number of autophagosomes (22-24). Previous studies have demonstrated that the PI3K/AKT/mTOR pathway plays a role in the occurrence and development of fibrosis of liver, kidney and other tissues (25-26).

The present study aimed to construct a rat model of Dox-induced myocardial damage and to determine whether Dox-induced myocardial fibrosis is associated with excessive ERS, autophagy and inhibits the PI3K/AKT/mTOR pathway signaling pathway. In addition, to determine if $\mathrm{H}_{2} \mathrm{~S}$ is able to improve Dox-induced myocardial fibrosis by regulating the $\mathrm{PI} 3 \mathrm{~K} / \mathrm{AKT} / \mathrm{mTOR}$ pathway to inhibit excessive autophagy.

\section{Materials and methods}

Experimental animals. A total of 40 adult male SD rats, weighing 200 $\pm 20 \mathrm{~g}$, were purchased from Changsha Lake Animal Experimental Central (Changsha, China). Prior to the construction of the model used, the rats were housed individually with sufficient ventilation under a 12-h light-dark cycle at $24 \pm 1^{\circ} \mathrm{C}$, and all the rats were allowed free access to food and water. The rats were fed in accordance with institutional policies and all the experiments were conducted with the approval granted by the University Committee on the Use and Care of Animals of University of South China (Hengyang, China).

Chemicals and reagents. NaHS was purchased from Sigma-Aldrich (Merck KGaA). Dox hydrochloride was supplied by Dalian Meilun Biology Technology Co., Ltd. PI3K p55, AKT1, mTOR, TGF- $\beta 1$, MMP2, TIMP2, TIMP3, cystathionine $\gamma$-lyase (CTH) and GAPDH were sourced from Wuhan Boster Biological Technology, Ltd., and used at a dilution of 1:500. Protein kinase RNA-like ER kinase (PERK), protein disulphide isomerase (PDI), DNA damage-inducible transcript 3 protein (DDIT-3) and ER chaperone $\mathrm{BiP}$ (BiP) were purchased from Cell Signaling Technology Inc., and used at a dilution of 1:1,000. Microtubule-associated proteins 1A/1B-light chain 3 (LC3), beclin-1, cysteine protease ATG4 (ATG4) and sequestosome-1 (P62) were purchased from ProteinTech Group Inc., and the dilution rate of these antibodies was 1:1,000. Anti-rat secondary antibody was purchased from KPL, Inc., and used at a dilution of 1:8,000. Cell lysis buffer for western blot analysis, BCA protein assay kit, Enhanced chemiluminescence reagent kit and SDS-PAGE gel preparation kit were sourced from Beyotime Institute of Biotechnology. The $\mathrm{H}_{2} \mathrm{~S}$ ELISA kit was supplied by Shanghai Enzyme-linked Biotechnology Co., Ltd.

Model establishment and grouping of rats. A total of 40 rats were allowed adaptive feeding for one week, and the general condition of all the rats, including food intake, mental state and weight change, was observed. All the rats were randomly divided into either the control group, Dox group, $\mathrm{H}_{2} \mathrm{~S}+$ Dox group or $\mathrm{H}_{2} \mathrm{~S}$ group, with each group comprising of 10 rats. Dox $(3.0 \mathrm{mg} / \mathrm{kg})$ was intraperitoneally injected 3 times/weekly for a total of 6 times in 2 weeks, to facilitate modeling in the Dox group, while in the $\mathrm{H}_{2} \mathrm{~S}+$ Dox group Dox was diluted to 
$0.5 \mathrm{mg} / \mathrm{ml}$ with $0.9 \% \mathrm{NaCl}$ before injection for immediate use. The same dose of normal saline was administered to the control and $\mathrm{H}_{2} \mathrm{~S}$ groups by intraperitoneal injection. Once the model had been successfully created, NaHS (56 $\mu \mathrm{mol} / \mathrm{kg} / \mathrm{day})$ was administered by intraperitoneal injection to the rats in the $\mathrm{H}_{2} \mathrm{~S}+$ Dox and $\mathrm{H}_{2} \mathrm{~S}$ group while the same dose of normal saline was administered intraperitoneally to the rats in the control and DOX groups.

Specimen collection and processing. After 8 weeks, the rats were weighed and echocardiography was completed. All rats were anesthetized with an intraperitoneal injection of $10 \%$ chloral hydrate $(300 \mathrm{mg} / \mathrm{kg}$ ) and subsequently sacrificed by cervical dislocation and the hearts were weighed after lavage with cold normal saline. The left ventricle of the heart was fixed in $10 \%$ neutral formalin at room temperature for $24 \mathrm{~h}$ and preserved at $4^{\circ} \mathrm{C}$ until further analysis. Ventricular muscle tissues $\left(1 \mathrm{~mm}^{2}\right)$ were sheared from the tissue, fixed in $2.5 \%$ glutaraldehyde solution at room temperature and preserved at $4^{\circ} \mathrm{C}$ until further analysis. Ventricular muscle tissue $\left(3 \mathrm{~mm}^{2}\right)$ was added to an adequate TRIzol ${ }^{\circledR}$ (Invitrogen; Thermo Fisher Scientific, Inc.), then placed in a sterile Eppendorf ${ }^{\circledR}$ tube without enzyme and stored at $-20^{\circ} \mathrm{C}$ for 1 month. The remaining tissue was stored at $-80^{\circ} \mathrm{C}$ for western blotting and ELISA for up to 1 year.

Echocardiography analysis. After weighing of the rats, transthoracic echocardiography was performed by a professional echocardiologist (Department of Ultrasound Imaging), who was blinded to the study. An evaluation of the left ventricular function was performed by recording and calculating the left ventricular end diastolic diameter (LVEDD), the left ventricular end systolic diameter (LVESD), the left ventricular ejection fraction (LVEF) and the left ventricular short-axis shortening rate (LVFS).

Masson staining. Myocardial tissue that had been previously fixed in $10 \%$ neutral formaldehyde solution was embedded in paraffin and cut into $\sim 4-\mu \mathrm{m}$ sections for MASSON staining. The tissue samples were dewaxed for hydration, then stained with hematoxylin for 5-10 $\mathrm{min}$ at room temperature, and rinsed with double-distilled water. Following which, the samples were washed with $1 \%$ hydrochloric acid-alcohol then double-distilled water, before being stained with Lichun red acid magenta for $10 \mathrm{~min}$ at room temperature, followed by an additional wash with double-distilled water. Subsequently $1 \%$ phosphomolybdic acid aqueous solution was added for differentiation, followed by staining with aniline blue for $5 \mathrm{~min}$ at room temperature. The samples were then incubated with $1 \%$ glacial acetic acid, and dehydrated in a gradient alcohol series (70 and 90\%), followed by washing with xylene and sealing with neutral gum. The samples were then viewed in multi-fields of view under a light microscope (magnification, $\mathrm{x} 400$ ) for comparison of the degree of myocardial fibrosis, which was reflected by the area of blue staining, in each of the 4 experimental groups of rats. The collagen fibers were stained dark blue.

Transmission electron microscopy (TEM). Myocardial tissues (1-mm thick) pre-fixed in $2.5 \%$ glutaraldehyde were dehydrated in an acetone series $(50 \%$ for $15 \mathrm{~min}, 70 \%$ for $15 \mathrm{~min}, 90 \%$ for $15 \mathrm{~min}, 100 \%$ for $10 \mathrm{~min}$ and $100 \%$ for $10 \mathrm{~min})$. After dehydration, pure acetone and the embedding solution were mixed at a ratio of 1:1. Myocardial tissue was incubated in the acetone-embedding solution mixture at $45^{\circ} \mathrm{C}$ for $12 \mathrm{~h}$, followed by incubation in embedding solution for $12 \mathrm{~h}$ and incubation at $45^{\circ} \mathrm{C}$ overnight. Subsequently, tissue sections were incubated at $60^{\circ} \mathrm{C}$ for $12-24 \mathrm{~h}$. Tissues were sliced and stained with $3 \%$ uranyl acetate and lead nitrate for 10-20 min at room temperature. Following washing with double distilled water, stained sections were observed using a transmission electron microscope.

Reverse transcription-quantitative $(R T-q) P C R$. Myocardial tissue frozen in TRIzol ${ }^{\circledR}$ (Invitrogen; Thermo Fisher Scientific, Inc.) was used. Total RNA was extracted according to the manufacturer's instructions. The purity and concentration of RNA was determined using an ultraviolet spectrophotometer. The reverse transcription kit was purchased from CWBio and used according to the manufacturer's instructions to obtain cDNA. GAPDH was used as the internal reference gene. The primer sequences for the genes were as follows: GAPDH (product length $252 \mathrm{bp}$ ) forward, 5'-ACAGCAACAGGGTGG TGGAC-3' and reverse, 5'-TTTGAGGGTGCAGCGAAC TT-3'; collagen type I $\alpha-2$ chain (COL1A2; product length $179 \mathrm{bp}$ ) forward, 5'-TTACCCTGGCAACATTGGTC-3' and reverse, 5'-CCTTGTCACCTCGAATACCTTG-3'; collagen type III $\alpha-1$ chain (COL3A1; product length $141 \mathrm{bp}$ ) forward, 5'-AAGGGCAGGGAACAACTGAT-3' and reverse 5'-GGT GAAGCAGGGTGAGAAGA-3'. The following was used for qPCR: $1 \mu \mathrm{l}$ Template (reverse transcript), $0.5 \mu \mathrm{l}$ forward primer $(10 \mu \mathrm{mol} / \mathrm{l}), 0.5 \mu \mathrm{l}$ reverse primer $(10 \mathrm{~mol} / \mathrm{l}), 13 \mu \mathrm{l} \mathrm{PCR}$ $\mathrm{H}_{2} \mathrm{O}$, and $15 \mu \mathrm{l} 2 \mathrm{X}$ SYBR-Green PCR mixture. The thermocycling conditions for PCR were as follows: Initial denaturation at $95^{\circ} \mathrm{C}$ for $10 \mathrm{~min}$, followed by 40 cycles of denaturation at $95^{\circ} \mathrm{C}$ for $5 \mathrm{sec}$ and annealing at $60^{\circ} \mathrm{C}$ for $30 \mathrm{sec}$. The data was analyzed by using the $2^{-\Delta \Delta \mathrm{Cq}}$ method.

ELISA. Myocardial tissue stored at $-80^{\circ} \mathrm{C}$ was used and the content of $\mathrm{H}_{2} \mathrm{~S}$ in the myocardial tissue was measured using $\mathrm{H}_{2} \mathrm{~S}$ content ELISA kit (cat. no. ml076943; Enzyme-linked Biotechnology Co., Shanghai, Ltd.) according to the manufacturer's instructions.

Western blot analysis. The left ventricular tissue that had been previously collected from each rats in the 4 experimental groups and stored at $-80^{\circ} \mathrm{C}$ were used. Proteins were extracted using Cell lysis buffer for Western and IP, PMSF (Beyotime Institute of Biotechnology) and protein was quantified using the BCA colorimetric method. The protein samples were heated at $99^{\circ} \mathrm{C}$ for $10 \mathrm{~min}$. Based on the molecular weight of the desired protein, an appropriate concentration of SDS-PAGE (8-12\%) was prepared, and proteins $(14 \mu \mathrm{l})$ were electrophoresed and transferred to PVDF membranes. The membranes were blocked using TBS-Tween-20 and then incubated with primary antibodies against TIMP2 (1:500), TIMP3 (1:500), MMP2 (1:500), PERK (1:1,000), DDIT-3 (1:1,000), BIP (1:1,000), PDI $(1: 1,000)$, Beclin-1 (1:1,000), LC3II $(1: 1,000)$, ATG4 (1:1,000), P62 (1:1,000), PI3K p55 (1:500), AKT1 (1:500), mTOR (1:500), TGF- $\beta 1$ (1:500) and GAPDH (1:500) at room temperature 

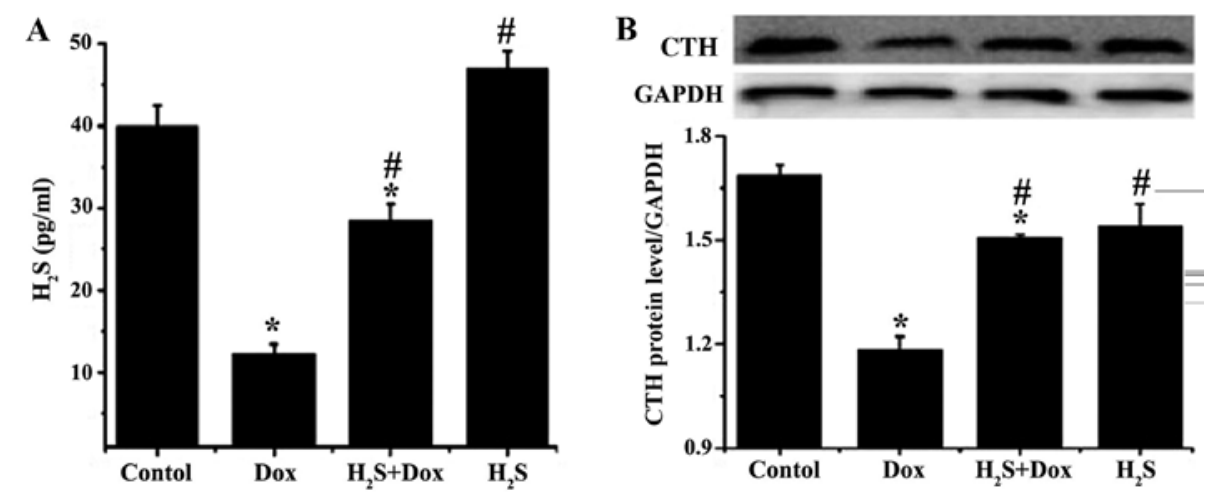

Figure 1. Quantification of myocardial $\mathrm{H}_{2} \mathrm{~S}$ content using ELISA and CTH expression level using western blot analysis in the 4 experimental groups. (A) Myocardial $\mathrm{H}_{2} \mathrm{~S}$ content. (B) $\mathrm{CTH}$ protein expression levels. Data are expressed as mean $\pm \mathrm{SD}(\mathrm{n}=3)$. ${ }^{*} \mathrm{P}<0.05$ vs. control group; ${ }^{*} \mathrm{P}<0.05$ vs. Dox group. $\mathrm{H}_{2} \mathrm{~S}$, hydrogen sulfide; $\mathrm{CTH}$, cystathionine $\gamma$-lyase; Dox, doxorubicin.

Table I. CVF in Masson staining in the 4 experimental groups ( $\mathrm{n}=3)$.

\begin{tabular}{lcccc}
\hline & \multicolumn{4}{c}{ Experimental group } \\
\cline { 2 - 5 } Characteristics & Control & Dox & $\mathrm{H}_{2} \mathrm{~S}+$ Dox & $\mathrm{H}_{2} \mathrm{~S}$ \\
\hline Mean CVF $\pm \mathrm{SD}$ & $3.34 \pm 0.71$ & $30.31 \pm 0.58^{\mathrm{a}}$ & $13.51 \pm 1.2^{\mathrm{a}, \mathrm{b}}$ & $4.67 \pm 0.22$ \\
\hline
\end{tabular}

${ }^{\mathrm{a}} \mathrm{P}<0.05$ vs. control group; ${ }^{\mathrm{P}}<0.05$ vs. Dox group. $\mathrm{H}_{2} \mathrm{~S}$, hydrogen sulfide; Dox, doxorubicin; $\mathrm{CVF}$, collagen volume fraction.

for $1 \mathrm{~h}$, followed by incubation at $4^{\circ} \mathrm{C}$ overnight. Following washing with TBST, the membranes were incubated with horseradish peroxidase-labeled rabbit secondary antibody $(1: 5,000)$ for $90 \mathrm{~min}$ at room temperature. Protein bands were visualized using an ECL kit, following rinsing with TBST. GAPDH was used as the internal reference and Grayscale scanning in the ImageJ software (version 1.8.0.112; National Institutes of Health) was performed to evaluate the protein expression level.

Statistical analysis. Statistical analysis was performed using SPSS v.18.0 software (SPSS, Inc.). The obtained data are expressed as the mean \pm standard deviation (SD). One-way ANOVA was used to analyze differences between multiple groups followed by the Tukey's post-hoc test. $\mathrm{P}<0.05$ was considered to indicate a statistically significant difference. All experiments were repeated three times.

\section{Results}

Mortality of rats in the experimental groups. During the duration of the experiment, a total of 7 rats died, including 4 in the Dox group and 3 in $\mathrm{H}_{2} \mathrm{~S}+$ Dox group. A large proportion of the deaths occurred in the late stage of the experiment, which is hypothesized to be associated with the increase of heart failure. However, the exact cause of death was unknown.

Amount of $\mathrm{H}_{2} \mathrm{~S}$ and CTH protein expression level in rat myocardial tissues of different experimental groups. ELISA was used to determine the amount of $\mathrm{H}_{2} \mathrm{~S}$ in the myocardium and to determine if it was associated with Dox-induced myocardial damage. The amount of $\mathrm{H}_{2} \mathrm{~S}$ in the Dox and $\mathrm{H}_{2} \mathrm{~S}+$ Dox groups was significantly reduced compared with that in the control group, while there was no significant difference in the $\mathrm{H}_{2} \mathrm{~S}$ group (Fig. 1). The amount of $\mathrm{H}_{2} \mathrm{~S}$ was significantly higher in the $\mathrm{H}_{2} \mathrm{~S}+$ Dox and $\mathrm{H}_{2} \mathrm{~S}$ groups compared with that in the Dox group. CTH is the major catalytic enzyme, which promotes $\mathrm{H}_{2} \mathrm{~S}$ synthesis in myocardial tissue (27). CTH expression was measured using western blot analysis and the results demonstrated that the protein expression level of CTH was consistent with that of $\mathrm{H}_{2} \mathrm{~S}$ in each experimental group (Fig. 1).

$\mathrm{H}_{2} \mathrm{~S}$ improves Dox-induced cardiac dysfunction in rats. LVEDD and LVESD were significantly increased in the Dox group compared with that in the control group (1.65 and $2.15 \mathrm{~mm}$, respectively; Fig. 2), while LVEF and LVFS were significantly reduced (21.60 and $19.00 \%$, respectively; Fig. 2). LVEDD and LVESD were significantly lower in $\mathrm{H}_{2} \mathrm{~S}+$ Dox group compared with that in the Dox group (0.99 and $1.07 \mathrm{~mm}$, respectively; Fig. 2), while LVEF and LVFS were substantially higher (9.50 and 5.90\%, respectively; Fig. 2).

$\mathrm{H}_{2} \mathrm{~S}$ improves Dox-induced myocardial fibrosis in rats. Using Masson staining, only minimally blue-stained fiber tissue was observed in both the control and $\mathrm{H}_{2} \mathrm{~S}$ group (Fig. 3). Myocardial cells were disorganized and myocardial fibers were markedly increased in the Dox group compared with the Control group, as the blue-stained area was increased (Fig. 3). Myocardial fibrosis improved in the $\mathrm{H}_{2} \mathrm{~S}+$ Dox group compared with that in the Dox group (Fig. 3). Additionally, the collagen volume fraction (CVF) of myocardial tissue present in each group was calculated using ImageJ software, which demonstrated that CVF in the Dox group was significantly higher compared with that in the control group, but was markedly reduced following 

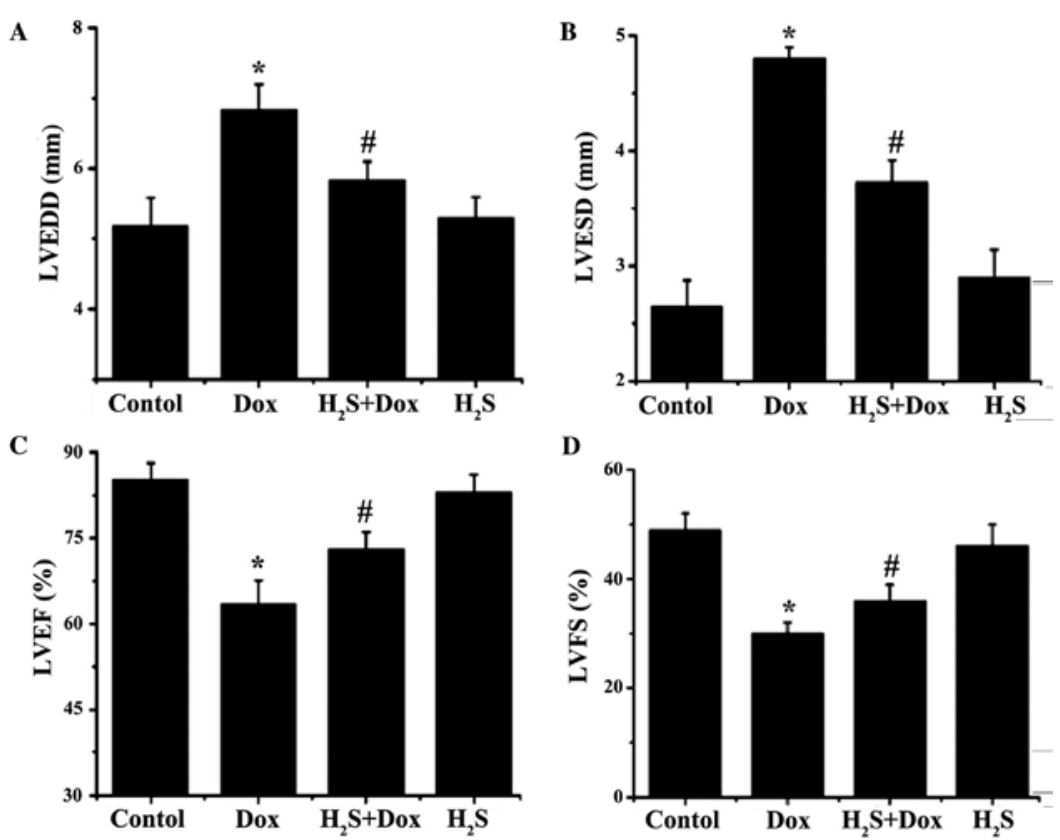

Figure 2. Comparison of the echocardiographic parameters in the 4 experimental groups. Data are expressed as mean \pm SD (n=3). (A) LVEDD. (B) LVESD. (C) LVEF. (D) LVFS. "P<0.05 vs. control group; ${ }^{*} \mathrm{P}<0.05$ vs. Dox group. LVEDD, left ventricular end diastolic diameter; LVESD, left ventricular end systolic diameter; LVEF, left ventricular ejection fraction; LVFS, left ventricular short-axis shortening rate; $\mathrm{H}_{2} \mathrm{~S}$, hydrogen sulfide; Dox, doxorubicin.

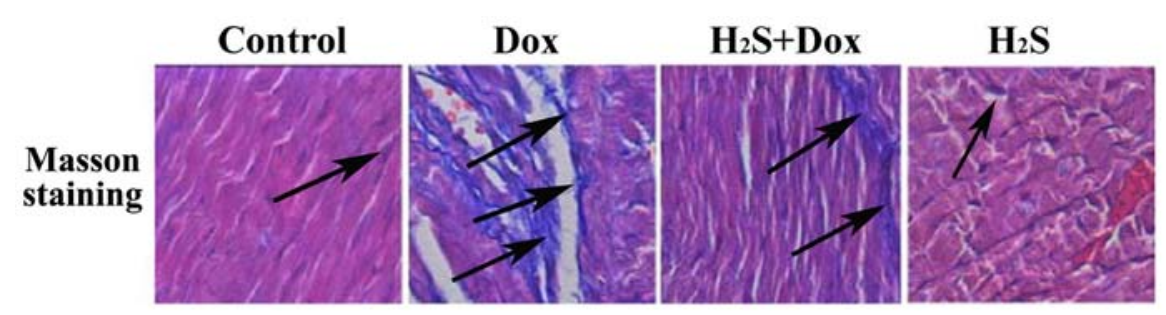

Figure 3. Morphological changes of the myocardium in the 4 experimental groups. Blue-stained areas indicated by the arrows are collagen fibers. Images were acquired at $\mathrm{x} 400$ magnification. $\mathrm{H}_{2} \mathrm{~S}$, hydrogen sulfide; Dox, doxorubicin.
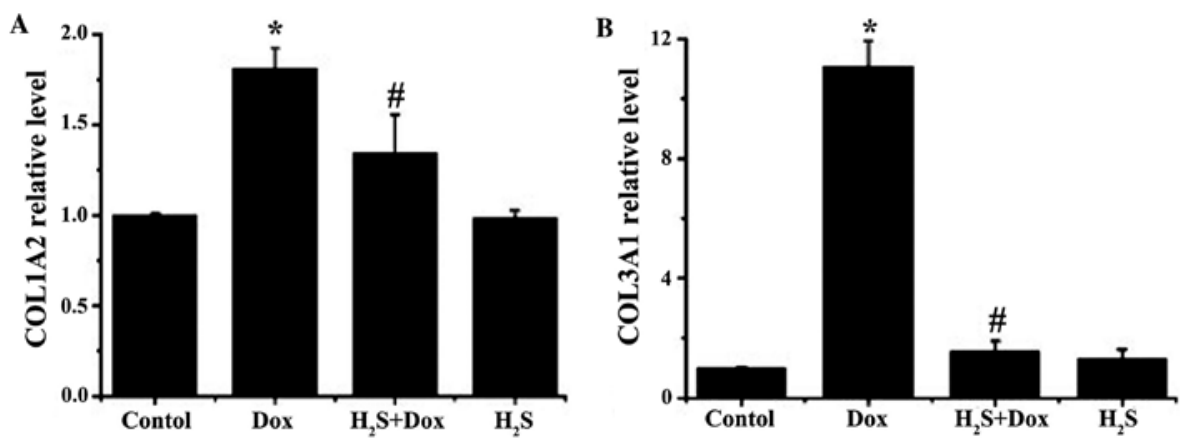

Figure 4. Gene expression levels of COL1A2 and COL3A1 in the 4 experimental groups. (A) COL1A2 and (B) COL3A1 mRNA expression levels. Data are expressed as mean $\pm \mathrm{SD}(\mathrm{n}=3)$. " $\mathrm{P}<0.05$ vs. control group; ${ }^{*} \mathrm{P}<0.05$ vs. Dox group. $\mathrm{H}_{2} \mathrm{~S}$, hydrogen sulfide; Dox, doxorubicin; COL1A2, collagen type I $\alpha-2$ chain; COL3A1, collagen type III $\alpha-1$ chain.

$\mathrm{H}_{2} \mathrm{~S}$ intervention. The CVF values of the control group were found to be similar to those of the $\mathrm{H}_{2} \mathrm{~S}$ group (Table I).

The mRNA expression levels of COL1A2 and COL3A1 in the myocardial tissue in each experimental group were detected using RT-qPCR and the results revealed that the expression levels of both genes in the Dox group were significantly increased compared with that in the control group; however, no significant difference was found in the $\mathrm{H}_{2} \mathrm{~S}$ group compared with that in the control group. The mRNA expression levels of COL1A2 and COL3A1 in the $\mathrm{H}_{2} \mathrm{~S}+$ Dox group was significantly reduced compared with that in the Dox group (Fig. 4).

The balance of MMPs/TIMPs plays a critical role in the synthesis and degradation of collagen, as well as the balance 

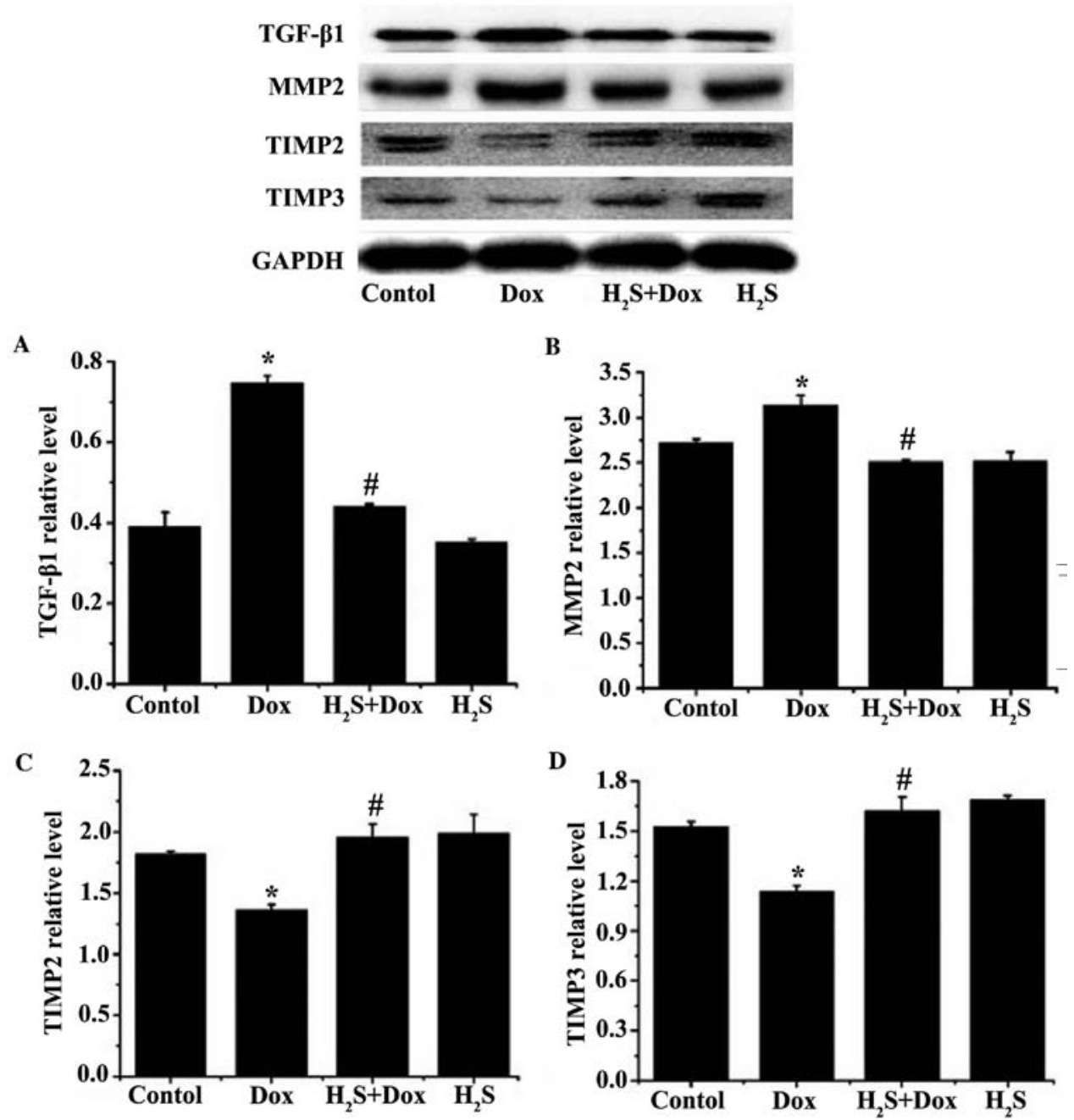

Figure 5. Protein expression levels of TGF- $\beta 1$, MMP2, TIMP2 and TIMP3 in the 4 experimental groups. Data are expressed as mean \pm SD ( $=3$ ). Protein expression levels of (A) TGF- $\beta 1$, (B) MMP2, (C) TIMP2 and (D) TIMP3. "P<0.05 vs. control group; " $\mathrm{P}<0.05$ vs. Dox group. $\mathrm{H}_{2} \mathrm{~S}$, hydrogen sulfide; Dox, doxorubicin; TGF, transforming growth factor; MMP, matrix metalloproteinase; TIMP, tissue inhibitor of matrix metalloproteinase.

of extracellular matrices. TGF- $\beta 1$ is a common mediator of myocardial fibrosis (28-29). The protein expression levels of MMP2 and TGF- $\beta 1$ were significantly increased in the Dox group, while the expression levels of TIMP2 and TIMP3 were significantly reduced compared with that in the control group (Fig. 5). The protein expression levels of MMP2 and TGF- $\beta 1$ were significantly reduced in $\mathrm{H}_{2} \mathrm{~S}+$ Dox group, while the protein expression levels of TIMP2 and TIMP3 were significantly increased in the $\mathrm{H}_{2} \mathrm{~S}+$ Dox group compared with that in the Dox group (Fig. 5). No significant difference was observed between the control and $\mathrm{H}_{2} \mathrm{~S}$ groups for any of the aforementioned proteins (Fig. 5).

Effects of $\mathrm{H}_{2} \mathrm{~S}$ on myocardial ultrastructure in rats with Dox-induced cardiomyopathy. TEM was used to observe myocardial fibers and autophagosomes in the 4 experimental groups. The myocardial tissues of the control and $\mathrm{H}_{2} \mathrm{~S}$ groups were arranged neatly with no edema or necrosis (Fig. 6). Part of the myocardial tissue in the Dox group displayed disorder of myocardial tissue, edema and lytic necrosis. In addition, a higher number of autophagosomes and autophagic vacuoles were observed in the Dox group compared with that in the control group. In the $\mathrm{H}_{2} \mathrm{~S}+$ Dox group, myocardial fiber arrangement disorder and edema were improved and the numbers of autophagosomes were lower compared with that in the Dox group (Fig. 6).

$\mathrm{H}_{2} \mathrm{~S}$ inhibits autophagy in rats with Dox-induced cardiomyopathy. The protein expression levels of beclin-1, LC3II and ATG4 were significantly increased in the Dox group compared with that in the control group (Fig. 7). In contrast, the expression level of P62 was significantly decreased in the Dox group compared with that in the control group (Fig. 7). There was no significant difference observed in the $\mathrm{H}_{2} \mathrm{~S}$ group compared with that in the control group for all the aforementioned proteins. The expression levels of beclin-1, LC3II and ATG4 were significantly reduced and the expression of P62 was significantly increased in the $\mathrm{H}_{2} \mathrm{~S}+$ Dox group compared with that in the Dox group (Fig. 7).

$\mathrm{H}_{2} \mathrm{~S}$ reduces ERS in rats with Dox-induced cardiomyopathy. The protein expression levels of DDIT-3, PDI, BIP, PERK in the Dox group were significantly increased compared with that in the control group (Fig. 8), while they were all significantly decreased in the $\mathrm{H}_{2} \mathrm{~S}+$ Dox group compared with that in the Dox group (Fig. 8). There was no significant difference in the 

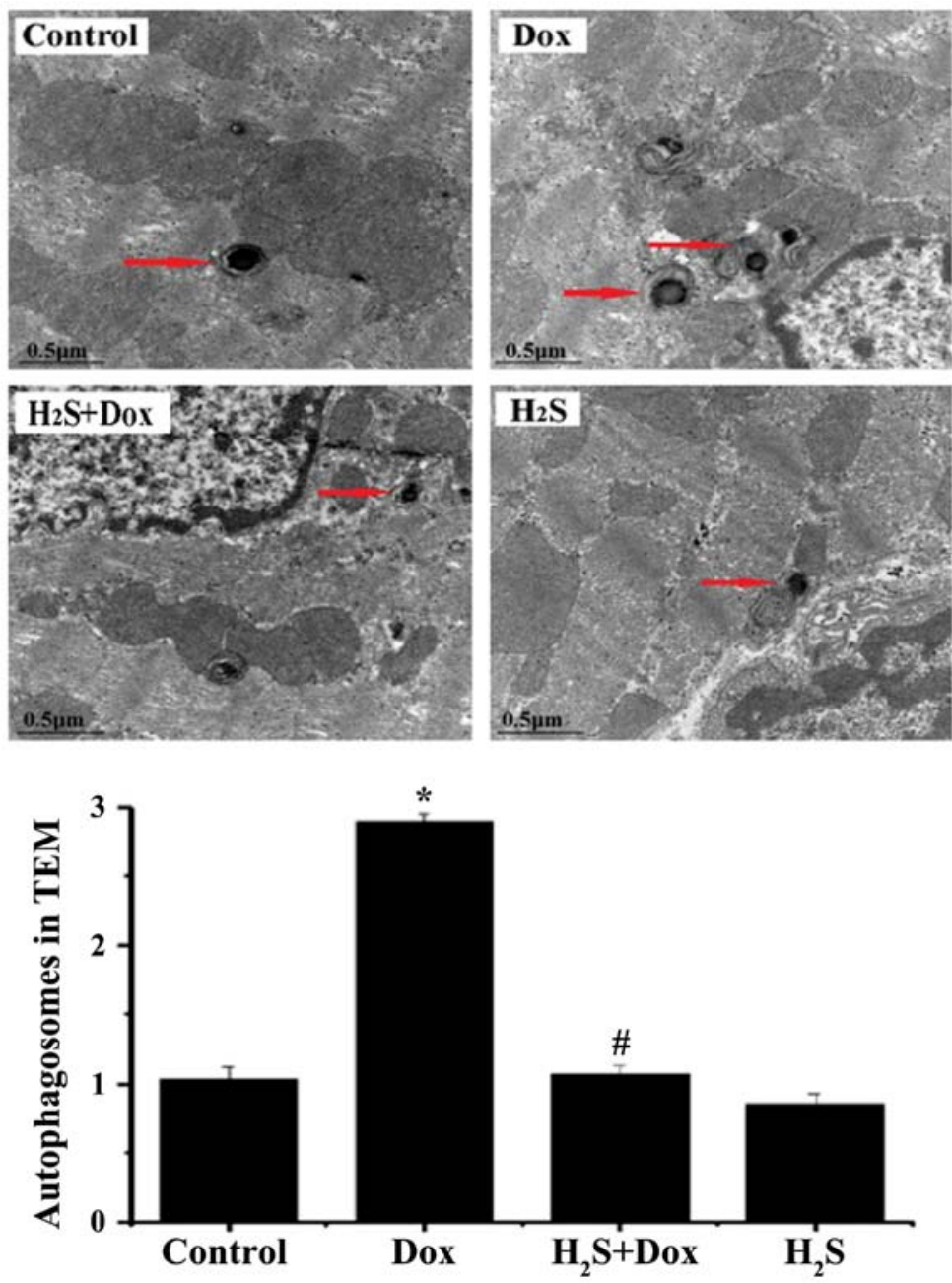

Figure 6. Transmission electron microscope of myocardial tissues from the 4 experimental groups. Red arrows indicate autophagosomes. Magnification, x20,000. ${ }^{*} \mathrm{P}<0.05$ vs. control; ${ }^{*} \mathrm{P}<0.05$ vs. Dox. $\mathrm{H}_{2} \mathrm{~S}$, hydrogen sulfide; Dox, doxorubicin.

aforementioned proteins between the control and $\mathrm{H}_{2} \mathrm{~S}$ groups (Fig. 8).

Effects of $\mathrm{H}_{2} \mathrm{~S}$ on Dox-induced change in the PI3K/AKT/mTOR signaling pathway. The protein expression levels of PI3Kp55, AKT1 and mTOR in the Dox group were significantly reduced compared with that in the control group (Fig. 9), while all the proteins were significantly increased in the $\mathrm{H}_{2} \mathrm{~S}+$ Dox group compared with that in the Dox group (Fig. 9). In addition, there was no significant difference in the aforementioned proteins between the control and $\mathrm{H}_{2} \mathrm{~S}$ groups (Fig. 9).

\section{Discussion}

Myocardial toxicity resulting from Dox treatment is increasingly common due to the widespread use of Dox in clinical practice, and myocardial fibrosis could provide a significant pathological basis for the development of Dox-induced myocardial toxicity (30). In the present study, a rat model of Dox-induced myocardial damage through intraperitoneal injection of Dox was successfully constructed. Furthermore, Masson staining demonstrated that collagenous fibers in myocardial interstitium were disorderly arranged and collagen deposition was significantly increased in the Dox group compared with the control group. RT-qPCR analysis was also performed, which demonstrated that the mRNA expression levels of COL1A2 and COL3A1 in the Dox group were significantly higher compared with that in the control group. In addition, western blot analysis demonstrated that the protein expression level of TGF- $\beta 1$ in myocardial tissue was higher in the Dox group compared with that in the control group, while the expression level of MMPs/TIMPs were dysregulated. Furthermore, ultrasonic cardiogram examination revealed the occurrence of myocardial remodeling and cardiac insufficiency in the rats of the Dox group. Collectively, these results demonstrated that myocardial structural and functional remodeling occurs in the myocardial tissues of rats following Dox induction and myocardial fibrosis is involved in the occurrence of Dox-induced myocardial damage. However, the mechanisms involved require further exploration.

At present, the mechanism of Dox-induced myocardial damage has not been adequately studied. Some studies have reported that ERS and autophagy play a role in the internal regulatory mechanism, Chen et al (31) reported that isodunnianol reduced myocardial damage caused by doxorubicin by activating protective autophagy, whereas Fu et al (32) reported that chemical endoplasmic reticulum chaperone molecules can alleviate Dox-induced cardiac dysfunction. miR378 

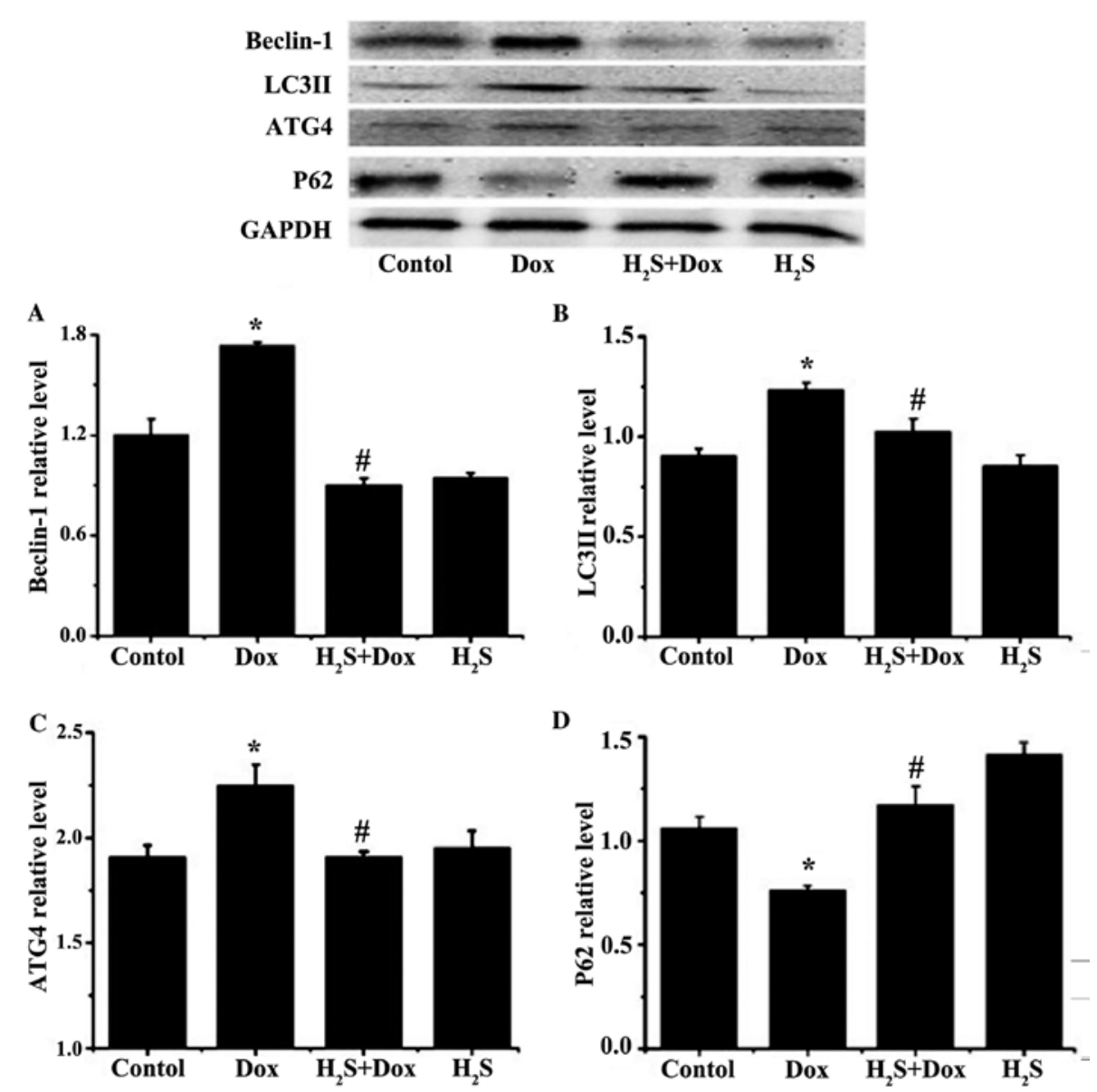

Figure 7. Protein expression levels of Beclin-1, LC3II, ATG4 and P62 in the 4 experimental groups. Protein expression levels of (A) Beclin-1, (B) LC3II, (C) ATG4 and (D) P62 were determined via western blotting. Data are expressed as mean $\pm \mathrm{SD}(\mathrm{n}=3)$. ${ }^{*} \mathrm{P}<0.05$ vs. control group; ${ }^{*} \mathrm{P}<0.05$ vs. Dox group. $\mathrm{H}_{2} \mathrm{~S}$, hydrogen sulfide; Dox, doxorubicin; LC3II-microtubule-associated protein 1A/1B-light chain 3; ATG4, cysteine protease ATG4; P62, sequestosome-1.

alleviates ERS and inhibits activation of the ERS-mediated apoptosis signaling pathway in cardiomyocytes via regulating calumenin expression, thereby reducing cardiomyocyte apoptosis after doxorubicin-induced injury (33). Another study reported that doxorubicin blocks autophagic flux in cardiomyocytes by impairing lysosome acidification and lysosomal function. Moreover, reducing autophagy initiation protects against doxorubicin cardiotoxicity (34). Moderate activation of ERS and autophagy is able to protect cells, while excessive activation has an opposite effect and results in cellular damage. Some studies have reported that ERS may induce cell autophagy through multiple molecular mechanisms (35-36). PERK, which acts as an ERS sensor and transmembrane protein kinase in the ER membrane is also part of a crucial pathway to induce ERS. PERK is similar to a transmembrane protein, as it can act as an intracellular receptor and stay on the ER membrane of animal cells and bind to the regulatory protein, $\mathrm{BiP}$, in the ER to form a stable complex, once stress has been detected, PERK dissociates with BiP and the activated PERK potentially regulates ERS-induced autophagy via the PERK-DDIT-3 signaling pathway (37). In another study, ERS was hypothesized to regulate autophagy by activating the PI3K pathway (38). Moreover, the findings of the present study revealed that in the Dox group, the protein expression levels of the ERS-related proteins, such as PERK, BiP, DDIT-3 and PDI were increased compared with the Control group. In addition, the expression levels of the autophagy-related proteins, such as Beclin-1, LC3II and ATG4 were also elevated, whereas P62 was significantly decreased in the Dox group compared with the Control group. In addition, TEM demonstrated that autophagosomes within cells were increased in the Dox Group compared with the control group, which indicated an upregulation of autophagy level. The excessive ERS and autophagy observed in the present study may play a role in the mechanism of Dox-induced myocardial damage.

The PI3K/AKT/mTOR pathway has a widespread distribution in cells and participates in various biological activities, such as cell proliferation, apoptosis, transcription, translation and the cell cycle. A previous study reported that the $\mathrm{PI} 3 \mathrm{~K} / \mathrm{AKT} / \mathrm{mTOR}$ pathway is also involved in the regulation of myocardial fibrosis (18). Some studies have revealed that the PI3K/AKT/mTOR pathway not only plays a role in the regulatory mechanism of differentiation of fibroblasts and interstitial deposition, but that it is also associated with the regulatory mechanism of autophagy (23-24). In the present study, although myocardial fibrosis was observed in the Dox group, the expression levels of proteins in the PI3K/AKT/mTOR pathway were significantly decreased. The expression levels of autophagy-related proteins, LC3B, Beclin-1 and ATG4, were significantly elevated while the expression level of p62 was reduced. These data suggest that the PI3K/AKT/mTOR 

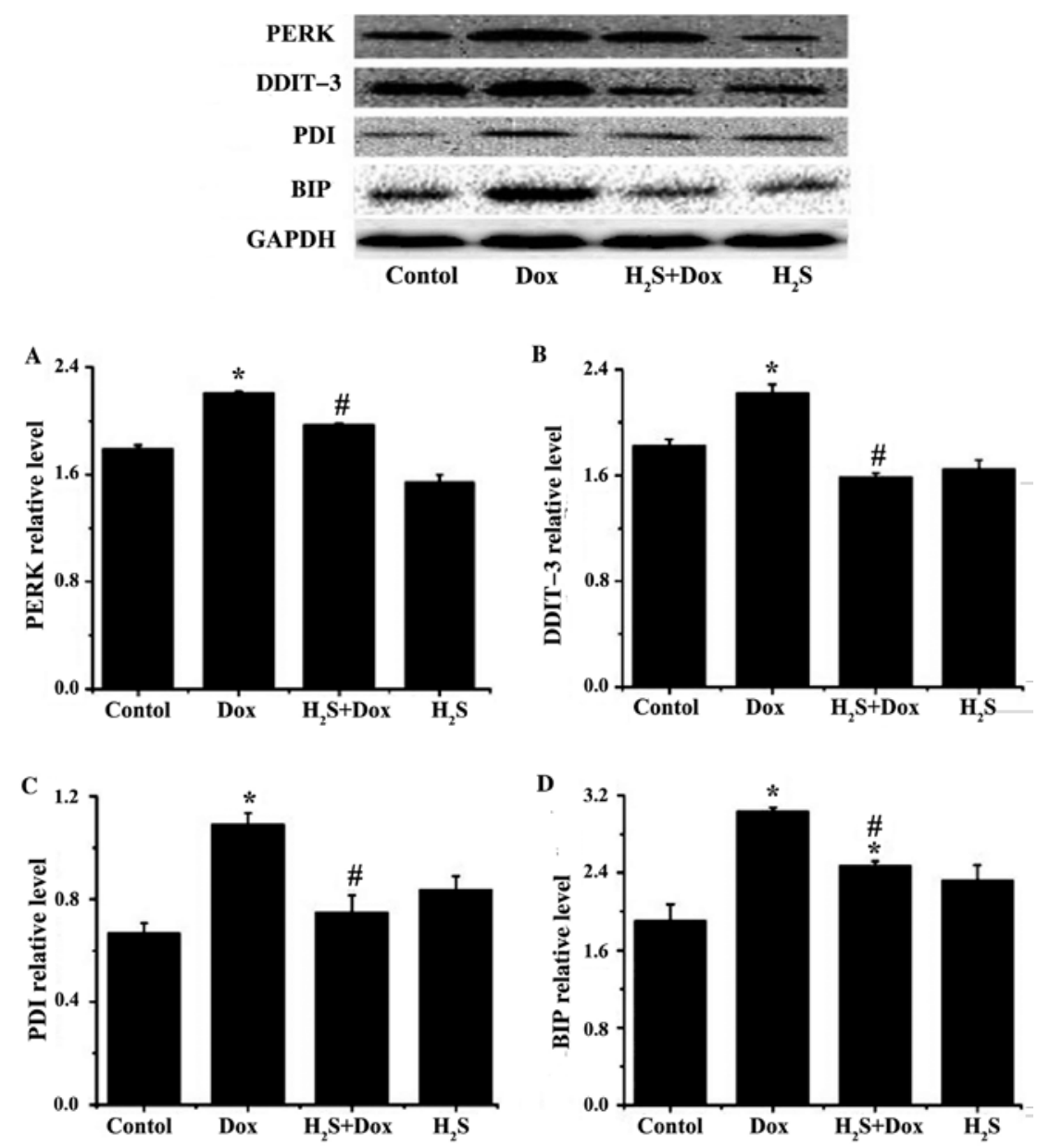

Figure 8. Protein expression levels of PDI, BIP, DDIT-3 and PERK in the 4 experimental groups. Protein expression levels of (A) PDI, (B) BIP, (C) DDIT-3 and (D) PERK were determined via western blotting. Data are expressed as mean $\pm \mathrm{SD}(\mathrm{n}=3)$. ${ }^{*} \mathrm{P}<0.05$ vs. control group; ${ }^{\text {}} \mathrm{P}<0.05$ vs. Dox group. $\mathrm{H}_{2} \mathrm{~S}$, hydrogen sulfide; Dox, doxorubicin; PERK, protein kinase RNA-like ER kinase; PDI, protein disulphide isomerase; DDIT-3, DNA damage-inducible transcript 3 protein; BiP, ER chaperone BiP; ER, endoplasmic reticulum.
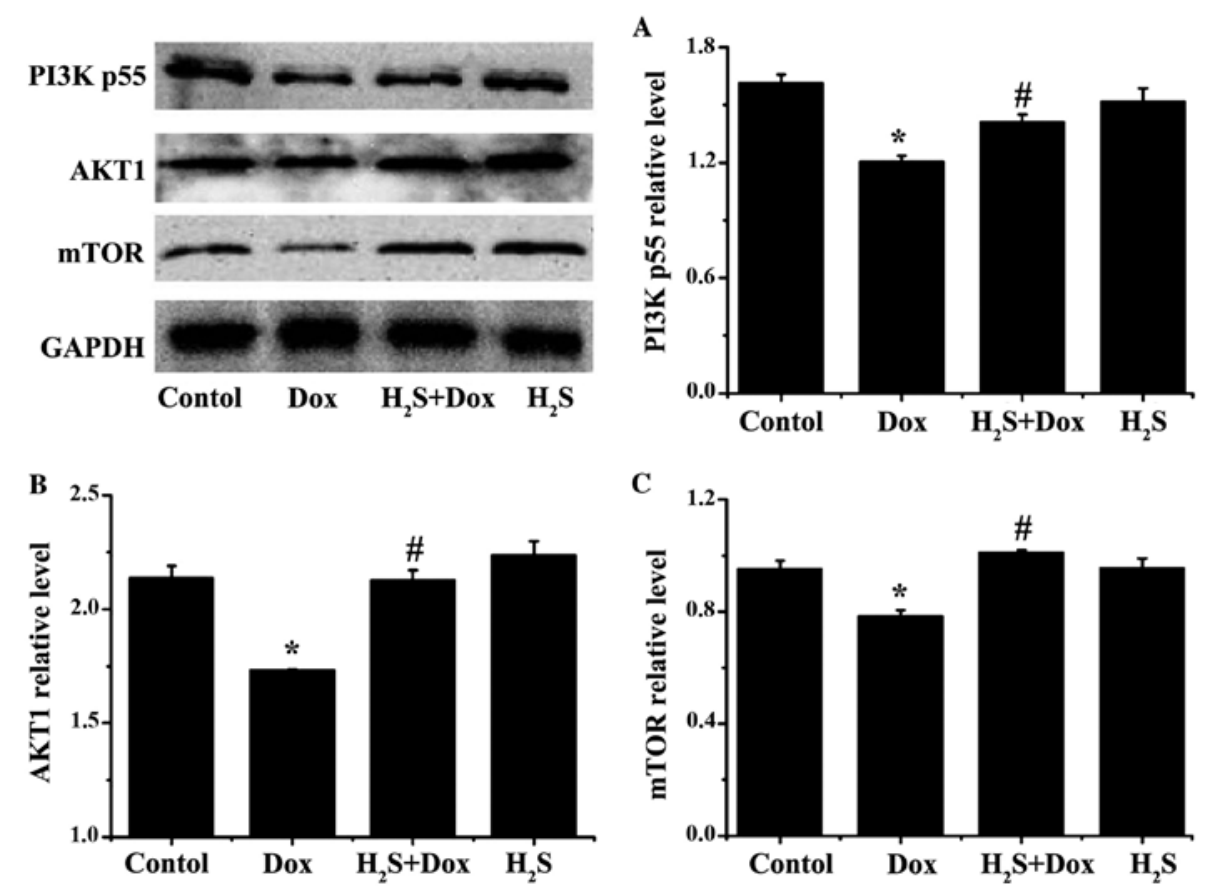

Figure 9. Protein expression levels of PI3K p55, AKT1 and mTOR in the 4 experimental groups. Protein expression levels of (A) PI3K p55, (B) AKT1 and (C) mTOR were determined via western blotting. Data are expressed as mean $\pm \mathrm{SD}(\mathrm{n}=3)$. ${ }^{*} \mathrm{P}<0.05$ vs. control group; ${ }^{\text {}} \mathrm{P}<0.05$ vs. Dox group. $\mathrm{H}_{2} \mathrm{~S}$, hydrogen sulfide; Dox, doxorubicin. 
pathway is associated with the regulatory mechanism of autophagy of injured myocardial cells induced by Dox.

Endogenous hydrogen sulfide is widely expressed in the tissues of the cardiovascular system and can be produced from $\mathrm{CTH}$ following the production of L-cysteine in myocardial cells. Numerous studies have been performed to demonstrate the physiological protective effect of CTH. In numerous pathological models, including hypertension, myocardial infarction and diabetic cardiomyopathy, both the changes in $\mathrm{CTH}$ production and the reduction in the level of endogenous $\mathrm{H}_{2} \mathrm{~S}$ have been observed (17-19). Using different internal mechanisms, the provision of an exogenous $\mathrm{H}_{2} \mathrm{~S}$ donor, such as NaHS, could significantly improve the level of $\mathrm{H}_{2} \mathrm{~S}$ and CTH within the human body, to produce a protective effect (17-19). In the present study, no significant difference in the amount of $\mathrm{H}_{2} \mathrm{~S}$ was found between $\mathrm{H}_{2} \mathrm{~S}$-treated and control rats. This could be due to the low dose of $\mathrm{H}_{2} \mathrm{~S}$ that was administered, which did not cause pathological damage, but subsequently had little effect on the total amount of $\mathrm{H}_{2} \mathrm{~S}$ under physiological conditions. However, whether $\mathrm{H}_{2} \mathrm{~S}$ is capable of inhibiting Dox-induced myocardial fibrosis and the internal mechanism involved remains unclear. In the present study following $\mathrm{H}_{2} \mathrm{~S}$ donor intervention, Dox-induced myocardial fibrosis in rats was notably improved, collagen deposition in myocardial interstitium was significantly reduced and the mRNA expression levels of COL1A2 and COL3A1 were reduced compared with that in the Dox group. MMPs/TIMPs imbalance was also markedly improved and the cardiac function of rats was restored to a certain degree, in the $\mathrm{H}_{2} \mathrm{~S}$ and Dox group compared with that in the Dox group. Additionally, following the addition of $\mathrm{H}_{2} \mathrm{~S}$, the expression levels of the ERS-related proteins, BIP, PERK, DDIT-3 and PDI were reduced, while those involved in the PI3K/AKT/mTOR pathway were increased and the autophagy-related proteins were significantly reduced. This indicates that exogenous $\mathrm{H}_{2} \mathrm{~S}$ can improve ERS and enhance Dox-induced myocardial fibrosis in rats by inhibiting excessive cell autophagy via the PI3K/AKT/mTOR pathway.

In the present study, it was discovered that $\mathrm{H}_{2} \mathrm{~S}$ can inhibit excessive autophagy and improve Dox-induced myocardial fibrosis by suppressing excessive ERS and activating the $\mathrm{PI} 3 \mathrm{~K} / \mathrm{AKT} / \mathrm{mTOR}$ pathway. This suggests that $\mathrm{H}_{2} \mathrm{~S}$, an endogenous gaseous signal molecule, serves an indispensable role in the protective mechanism of Dox-induced myocardial damage and myocardial fibrosis by regulating ERS and autophagy. In addition, promoting endogenous $\mathrm{H}_{2} \mathrm{~S}$ production and providing exogenous $\mathrm{H}_{2} \mathrm{~S}$ can reduce the occurrence of Dox-induced myocardial damage and myocardial fibrosis, as well as DCM in rats. Therefore, the present study provides a basis for a greater understanding of the pathogenesis of Dox-induced cardiomyopathy and assists in identifying a novel intervention target for the prevention and diagnosis of Dox-induced cardiomyopathy. There are some limitations to the present study. Firstly, it only explored the protective mechanism of Dox-induced myocardial fibrosis using in vivo experiments. Thus, future in vitro experiments would be required, which would include using $\mathrm{H}_{2} \mathrm{~S}$ inhibitors, signal pathway-specific intervention factors and gene knockout to further clarify the pathological mechanism involved and provide more clinical guidance for Dox-induced cardiomyopathy.

\section{Acknowledgements}

Not applicable.

\section{Funding}

The present study was supported by the National Natural Science Foundation of China (grant no. 81870230) and the Hunan Graduate Research and Innovation Project (grant no. CX20190765).

\section{Availability of data and materials}

The datasets used and/or analyzed during the current study are available from the corresponding author on reasonable request.

\section{Authors' contributions}

LN and ML performed the experiments, led the experimental design and participated in drafting the manuscript. JC, QW, YL and JYi performed the experiments. XZ and JZ conducted the literature searches, and completed the verification and revision of important knowledge content. CC and JYa helped with designing the study, critically revising the manuscript and approving the final version of the manuscript. $\mathrm{LN}$ and $\mathrm{ML}$ confirm the authenticity of all the raw data. All authors have read and approved the final manuscript.

\section{Ethics approval and consent to participate}

This study was granted ethical approval by the University Committee on the Use and Care of Animals of University of South China (Hengyang, China).

\section{Patient consent for publication}

Not applicable.

\section{Competing interests}

The authors declare that they have no competing interests.

\section{References}

1. Jefferies JL and Towbin JA: Dilated cardiomyopathy. Lancet 375: 752-762, 2010.

2. Geng C, Cui C, Wang C, Lu S, Zhang M, Chen D and Jiang P: Systematic evaluations of doxorubicin-induced toxicity in rats based on metabolomics. ACS Omega 6: 358-366, 2021.

3. Xia Y, Chen Z, Chen A, Fu M, Dong Z, Hu K, Yang X, Zou Y, Sun A, Qian J and Ge J: LCZ696 improves cardiac function via alleviating Drp1-mediated mitochondrial dysfunction in mice with doxorubicin-induced dilated cardiomyopathy. J Mol Cell Cardiol 108: 138-148, 2017.

4. Yao YF, Liu X, Li WJ, Shi ZW, Yan YX, Wang LF, Chen M and Xie MY: (-)-Epigallocatechin-3-gallate alleviates doxorubicin-induced cardiotoxicity in sarcoma 180 tumor-bearing mice. Life Sci 180: 151-159, 2017.

5. Wang X, Li C, Wang Q, Li W, Guo D, Zhang X, Shao M, Chen X, Ma L, Zhang Q, et al: Tanshinone IIA restores dynamic balance of autophagosome/autolysosome in doxorubicin-induced cardiotoxicity via targeting beclin1/LAMP1. Cancers (Basel) 11: 910, 2019. 
6. Hasinoff BB, Patel D and Wu X: A QSAR study that compares the ability of bisdioxopiperazine analogs of the doxorubicin cardioprotective agent dexrazoxane (ICRF-187) to protect myocytes with DNA topoisomerase II inhibition. Toxicol Appl Pharmacol 399: 115038, 2020.

7. Gava FN, Zacché E, Ortiz EMG, Champion T, Bandarra MB Vasconcelos RO, Barbosa JC and Camacho AA: Doxorubicin induced dilated cardiomyopathy in a rabbit model: An update. Res Vet Sci 94: 115-121, 2013.

8. Yu Q, Li Q, Na R, Li X, Liu B, Meng L, Liutong H, Fang W, Zhu $\mathrm{N}$ and Zheng $\mathrm{X}$ : Impact of repeated intravenous bone marrow mesenchymal stem cells infusion on myocardial collagen network remodeling in a rat model of doxorubicin-induced dilated cardiomyopathy. Mol Cell Biochem 387: 279-285, 2014

9. Wu X, Qi X, Lu Y, Lin C, Yuan Y, Zhu Q, Yin Q, Li W, Li Y and Bian H: Liguzinediol protects against cardiac fibrosis in rats in vivo and in vitro. Biomed Pharmacother 80: 260-267, 2016.

10. Liu S, Chen S, Li M, Zhang B, Shen P, Liu P, Zheng D, Chen Y and Jiang J: Autophagy activation attenuates angiotensin II-induced cardiac fibrosis. Arch Biochem Biophys 590: 37-47, 2016

11. Li SJ, Liu CH, Chu HP, Mersmann HJ, Ding ST, Chu CH, Wang CY and Chen CY: The high-fat diet induces myocardial fibrosis in the metabolically healthy obese minipigs-The role of ER stress and oxidative stress. Clin Nutr 36: 760-767, 2017.

12. Zeglinski MR, Davies JJL, Ghavami S, Rattan SG, Halayko AJ and Dixon IMC: Chronic expression of Ski induces apoptosis and represses autophagy in cardiac myofibroblasts. Biochim Biophys Acta 1863: 1261-1268, 2016.

13. González A, López B, Ravassa S, San José G and Díez J: The complex dynamics of myocardial interstitial fibrosis in heart failure. Focus on collagen cross-linking. Biochim Biophys Acta Mol Cell Res 1866: 1421-1432, 2019.

14. Yang R, Jia Q, Ma SF, Wang Y, Mehmood S and Chen Y: Exogenous $\mathrm{H} 2 \mathrm{~S}$ mitigates myocardial fibrosis in diabetic rats through suppression of the canonical Wnt pathway. Int J Mol Med 44: 549-558, 2019.

15. Song $\mathrm{H}$ and Ren J: Protocatechuic acid attenuates angiotensin II-induced cardiac fibrosis in cardiac fibroblasts through inhibiting the NOX4/ROS/p38 signaling pathway. Phytother Res 33: 2440-2447, 2019.

16. Russo I, Cavalera M, Huang S, Su Y, Hanna A, Chen B, Shinde AV, Conway SJ, Graff J and Frangogiannis NG: Protective effects of activated myofibroblasts in the pressure-overloaded myocardium are mediated through smad-dependent activation of a matrix-preserving program. Circ Res 124: 1214-1227, 2019.

17. Xiao T, Zeng O, Luo J, Wu Z, Li F and Yang J: Effects of hydrogen sulfide on myocardial fibrosis in diabetic rats: Changes in matrix metalloproteinases parameters. Biomed Mater Eng 26 (Suppl 1) S2033-S2039, 2015.

18. Liu M, Li Z, Liang B, Li L, Liu S, Tan W, Long J, Tang F, Chu C and Yang J: Hydrogen sulfide ameliorates rat myocardial fibrosis induced by thyroxine through PI3K/AKT signaling pathway. Endocr J 65: 769-781, 2018.

19. Liang B, Xiao T, Long J, Liu M, Li Z, Liu S and Yang J: Hydrogen sulfide alleviates myocardial fibrosis in mice with alcoholic cardiomyopathy by downregulating autophagy. Int J Mol Med 40: 1781-1791, 2017.

20. Miricescu D, Totan A, Stanescu-Spinu II, Badoiu SC, Stefani C and Greabu M: PI3K/AKT/mTOR signaling pathway in breast cancer: From molecular landscape to clinical aspects. Int J Mol Sci 22: 173,2020

21. Zhang N, Zhang J, Tan YQ, Du GF, Lu R and Zhou G: Activated Akt/mTOR-autophagy in local T cells of oral lichen planus. Int Immunopharmacol 48: 84-90, 2017.

22. Heras-Sandoval D, Pérez-Rojas JM, Hernández-Damián J and Pedraza-Chaverri J: The role of PI3K/AKT/mTOR pathway in the modulation of autophagy and the clearance of protein aggregates in neurodegeneration. Cell Signal 26: 2694-2701, 2014.
23. Thellung S, Corsaro A, Nizzari M, Barbieri F and Florio T: Autophagy activator drugs: A new opportunity in neuroprotection from misfolded protein toxicity. Int J Mol Sci 20: 901, 2019.

24. Rashid HO, Yadav RK, Kim HR and Chae HJ: ER stress: Autophagy induction, inhibition and selection. Autophagy 11: 1956-1977, 2015

25. Huang TJ, Ren JJ, Zhang QQ, Kong YY, Zhang HY, Guo XH, Fan HQ and Liu LX: IGFBPrP1 accelerates autophagy and activation of hepatic stellate cells via mutual regulation between H19 and PI3K/AKT/mTOR pathway. Biomed Pharmacother 116: $109034,2019$.

26. Kim CS, Kim IJ, Choi JS, Bae EH, Ma SK and Kim SW: Tamoxifen ameliorates obstructive nephropathy through Src and the PI3K/Akt/mTOR pathway. Biol Cell 111: 18-27, 2019.

27. Szabo C: Hydrogen sulfide, an endogenous stimulator of mitochondrial function in cancer cells. Cells 10: 220, 2021

28. Polyakova V, Loeffler I, Hein S, Miyagawa S, Piotrowska I, Dammer S, Risteli J, Schaper J and Kostin S: Fibrosis in endstage human heart failure: Severe changes in collagen metabolism and MMP/TIMP profiles. Int J Cardiol 151: 18-33, 2011.

29. El Hajj EC, El Hajj MC, Voloshenyuk TG, Mouton AJ, Khoutorova E, Molina PE, Gilpin NW and Gardner JD: Alcohol modulation of cardiac matrix metalloproteinases (MMPs) and tissue inhibitors of MMPs favors collagen accumulation. Alcohol Clin Exp Res 38: 448-456, 2014.

30. Wu WY, Cui YK, Hong YX, Li YD, Wu Y, Li G, Li GR and Wang Y: Doxorubicin cardiomyopathy is ameliorated by acacetin via Sirt1-mediated activation of AMPK/Nrf2 signal molecules. J Cell Mol Med 24: 12141-12153, 2020.

31. Chen C, Jiang L, Zhang M, Pan X, Peng C, Huang W and Jiang Q: Isodunnianol alleviates doxorubicin-induced myocardial injury by activating protective autophagy. Food Funct 10: 2651-2657, 2019.

32. Fu HY, Sanada S, Matsuzaki T, Liao Y, Okuda K, Yamato M, Tsuchida S, Araki R, Asano Y, Asanuma H, et al: Chemical endoplasmic reticulum chaperone alleviates doxorubicin-induced cardiac dysfunction. Circ Res 118: 798-809, 2016.

33. Wang Y, Cui X, Wang Y, Fu Y, Guo X, Long J, Wei C and Zhao M: Protective effect of miR378* on doxorubicin-induced cardiomyocyte injury via calumenin. J Cell Physiol 233: 6344-6351, 2018

34. Li DL, Wang ZV, Ding G, Tan W, Luo X, Criollo A, Xie M, Jiang N, May H, Kyrychenko V, et al: Doxorubicin blocks cardiomyocyte autophagic flux by inhibiting lysosome acidification. Circulation 133: 1668-1687, 2016.

35. Song S, Tan J, Miao Y and Zhang Q: Crosstalk of ER stress-mediated autophagy and ER-phagy: Involvement of UPR and the core autophagy machinery. J Cell Physiol 233: 3867-3874, 2018.

36. Deegan S, Saveljeva S, Gorman AM and Samali A: Stress-induced self-cannibalism: On the regulation of autophagy by endoplasmic reticulum stress. Cell Mol Life Sci 70: 2425-2441, 2013.

37. Yu X and Long YC: Autophagy modulates amino acid signaling network in myotubes: Differential effects on mTORC1 pathway and the integrated stress response. FASEB J 29: 394-407, 2015.

38. Li LJ, Chai Y, Guo XJ, Chu SL and Zhang LS: Effects of endoplasmic reticulum stress on autophagy and apoptosis of human leukemia cells via inhibition of the PI3K/AKT/mTOR signaling pathway. Mol Med Rep 17: 7886-7892, 2018.

This work is licensed under a Creative Commons Attribution-NonCommercial-NoDerivatives 4.0 International (CC BY-NC-ND 4.0) License. 